Original Research Article

\title{
Awareness of rational use of medicines among interns at rural teaching hospital
}

\author{
Thiruganahalli Padmanabha Shivaraju, Madhav K. Savkar*
}

Department of Pharmacology, Adichunchanagiri Institute of Medical Sciences,

Adichunchanagiri University, BG Nagara 571448,

Nagamangala, Mandya,

Karnataka, India

Received: 04 September 2018

Revised: 21 September 2018

Accepted: 27 September 2018

*Correspondence to:

Dr. Madhav K. Savkar,

Email: savkarmk@gmail.com

Copyright: (C) the author(s), publisher and licensee Medip Academy. This is an openaccess article distributed under the terms of the Creative Commons Attribution NonCommercial License, which permits unrestricted noncommercial use, distribution, and reproduction in any medium, provided the original work is properly cited.

\begin{abstract}
Background: The concern of switching irrational towards rational prescribing behaviour by prescriber impacts the patient compliance. Thereby an attempt to bring down the drug resistance is possible. Aim and objective of the study was to know the knowledge and practices Rational prescription behaviour in medical interns (MBBS 2012 batch) at Adichunchanagiri Institute of Medical Sciences (AIMS), BG Nagara.

Methods: Observational cross sectional validated questionnaire based study on Rational Use of Medicines (RUM) was administered to Interns $(n=75)$ included both males and females (MBBS 2012 batch) at AIMS during March-April 2018. Results: Both the gender had similar knowledge on RUM. 32 (42.67\%) male and $43(57.33 \%)$ female interns participated and $88 \%$ were aware of term "Essential drug". Though $61.33 \%$ were prescribing rationally, they lacked in terms of listing National essential drug list and steps involved in selecting "P-drug". Only 4\% rightly defined RUM. 92\% agreed that RUM minimizes ADR incidence. 90.67\% believed that RUM would reduce the development of drug resistance. And $85.33 \%$ were in opinion that doctors should use his/her gained knowledge despite of Medical representative advice to bring the justice towards RUM in practice before prescribing.

Conclusions: Rational use of medicine in interns should be assessed periodically on prescribing knowledge and skills during their training to minimize prescribing and clinical errors.
\end{abstract}

Keywords: Essential medicines, Interns, P drug, Rational use of medicines

\section{INTRODUCTION}

Patients receive medications appropriate to their clinical needs, in doses that meet their own individual requirements, for an adequate period of time, and at the lowest cost to them and their community." (WHO,1985). Rational use of medicine is the integral system in health care, which has become the weakest part in practicing physician that has led to irrational and increased the patient's socio -economic burden. ${ }^{1}$

Though irrational use of medicine may look like a tip of an iceberg, but when we look beneath the pseudo projection their lies the big global problem of appropriate use of drug. At many times more than half of the prescription, dispensing practices are inappropriate with failure to educate patients for the right way to use them. Because of such rampant insane behavior, and resources are being wasted, which has to be dealt with serious concern to prevent the hazardous consequences. ${ }^{1}$

Irrational use is influenced by various diverse factors like patient belief of "a pill for every ill", poor prescriber training for example prescribing antimotility drugs for acute infective diarrhoea, work place setting such pressure to reach target, poor resource, lack of staff in spite of their competency, aggressive pharmaceutical publicity and 
marketing, about $87 \%$ authors of 'Clinical Practice Guidelines' had some form of interaction with drug company representatives that may impact the irrational prescription practice on day to day basis., ${ }^{2,3}$

At an outlook irrational use as got a lot of impact on individual, community, natural resources. Level of impact may range from a mere side effects to life threatening consequences leading to longer hospitalization, which would disturb the socio-economic and psychosocial status as well ecological imbalance with wastage of valuable scanty resources. ${ }^{4,5}$

Therefore because of the dearth of knowledge towards the Rational use of medicine we undertook a study among interns to determine their knowledge of rational use of medicine so that the future young doctors might prescribe rationally.

Aim of the study was to assess the knowledge of 'Rational Use of Medicine' (RUM) practices in interns at Adichunchanagiri Institute Medical Sciences teaching hospital, BG Nagara.

\section{Objectives}

- To assess the knowledge status on RUM.

- To understand the behaviour of practice followed by interns during their training session.

\section{METHODS}

The questionnaire base observational cross-sectional study on Rational Use of Medicines was carried out among seventy five $(n=75)$ interns (MBBS 2012 batch) at Adichunchanagiri Institute of Medical Sciences, B G Nagara, Mandya, Karnataka after taking Institutional Ethics Committee approval during March -April 2018 by Department of Pharmacology. Consent was taken from participants before filling the questionnaire. Inclusion criteria: Both male and female interns who cleared phase3, part-II and willing to participate were included. Exclusion criteria: those not willing to participate, other phases of MBBS students and those students who have not cleared phase-3, part-II was excluded. Questionnaire was prepared from various earlier published literatures and was validated. ${ }^{6,7}$ Questionnaire contained twenty six items (kindly refer Annexure 1 and Table 1) related to factors like essential drugs, P-drug concept, advantages of RUM, prescription habit, adverse drug reaction, cost, benefit, effectiveness, drug promotional materials and medical representatives (MRs). Methodology used was cross sectional observational, qualitative study and 15-20 minutes time was given to fill the questionnaire which had yes or no; 5-point Likert scale (strongly agree, agree, neutral, disagree, strongly disagree) type of options to known the relationship between RUM and adverse drug reaction consequences and few questions had only three options (e.g.: always, frequently and occasionally; new drug, old drug, both; generic name, brand name and both; yes, no and not sure). Students were told to ask about any queries related to the study freely to the investigators. And assured that the results from the present study will be used for academic enrichment purpose and for publication without having any intention of monetary benefits. Individual responses were analyzed and overall responses were combined. The results were tabulated, analyzed and expressed in percentages (\%) in the form of bar diagram, pie chart and column diagram. Graphical representation was made wherever necessary using Microsoft Office Excel 2017 and Microsoft Office Word 2007.

\section{RESULTS}

Response rate to questionnaire based survey was $100 \%$ $(\mathrm{n}=75)$, which includes $32(42.67 \%)$ males and 43 $(57.33 \%)$ females interns, and overall $88 \%$ of them were aware of the term essential drugs. About $49.33 \%$ were aware of essential medicines. 57.33\% said they prescribe according to essential drug list, India and aware of term RUM. Just 33.33\% knew that National Model Essential Drug List exists at their workplace.

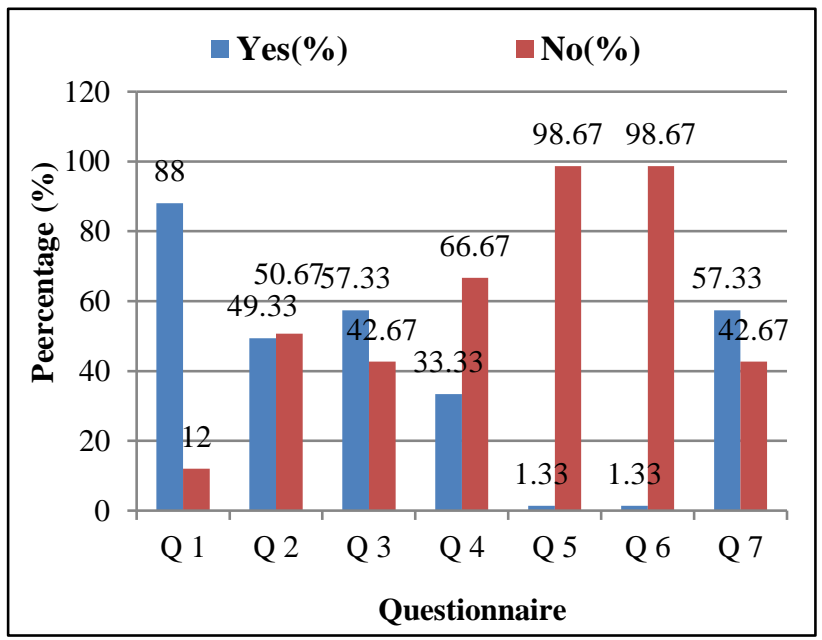

Figure 1: RUM questionnaire 1 to 7.

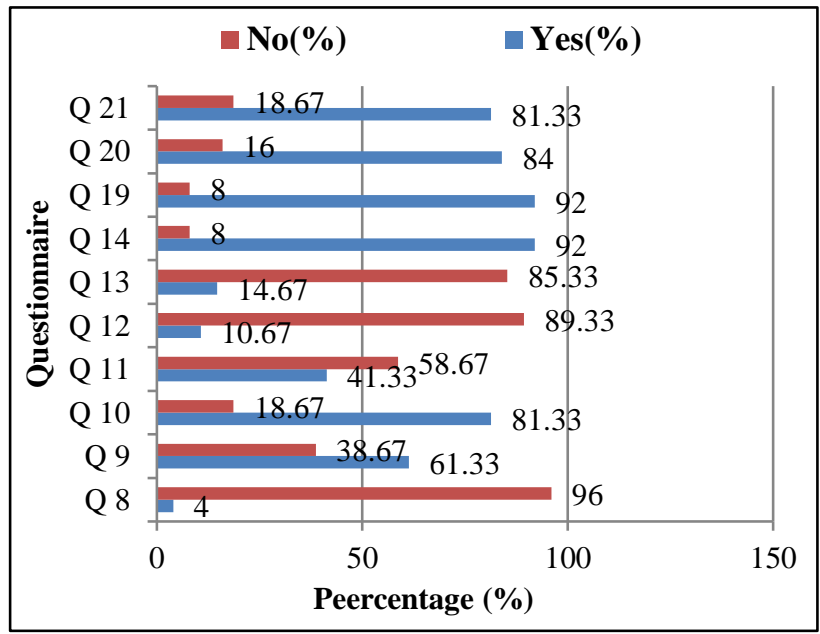

Figure 2: RUM questionnaire 8 to14 and 19 to 21. 
Merely $1.3 \%$ had knowledge of total number of drugs and fixed dose combination listed under EML (Figure 1). $81.33 \%$ aware of the drug ingredients and give adverse effect information. $84 \%$ said they check details of the drugs while prescribing. Taking care of drug therapy, follow-up, management and writing all the parts of prescription was followed by $92 \%$ (Figure 2).

In the study, $58.67 \%, 89.33 \%$ and $85.33 \%$ were not aware of P drug, STEP criteria to select P drug and advantages of it respectively. Majority of them about $96 \%$ were not knowing how to define RUM (Figure 2). $50.67 \%$ were in habit of frequently prescribing from EML and $48 \%$ were knowing adverse effect, interactions and contraindications of drug they prescribe (Figure 3 ).

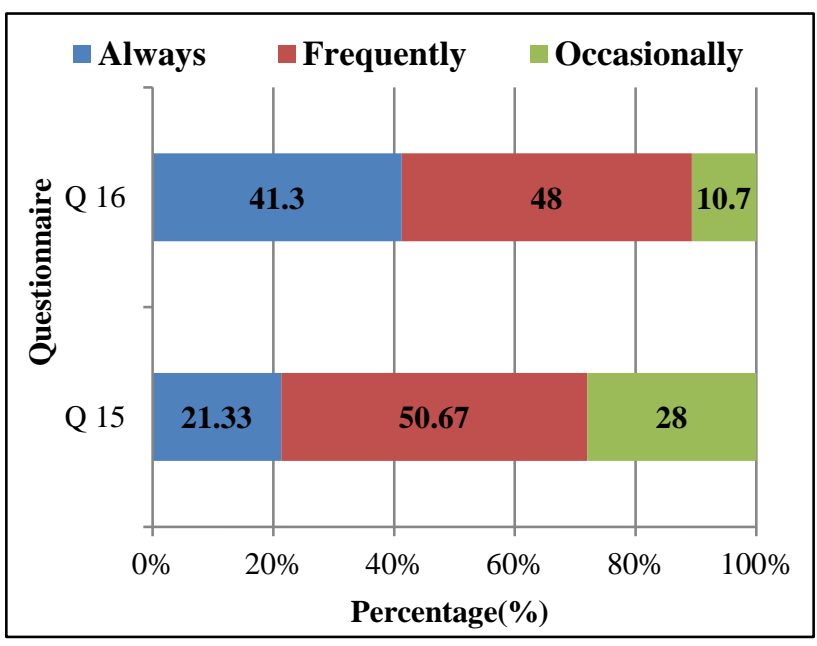

Figure 3: RUM questionnaire 15 (essential medicine prescription) and 16 (adverse effect awareness).

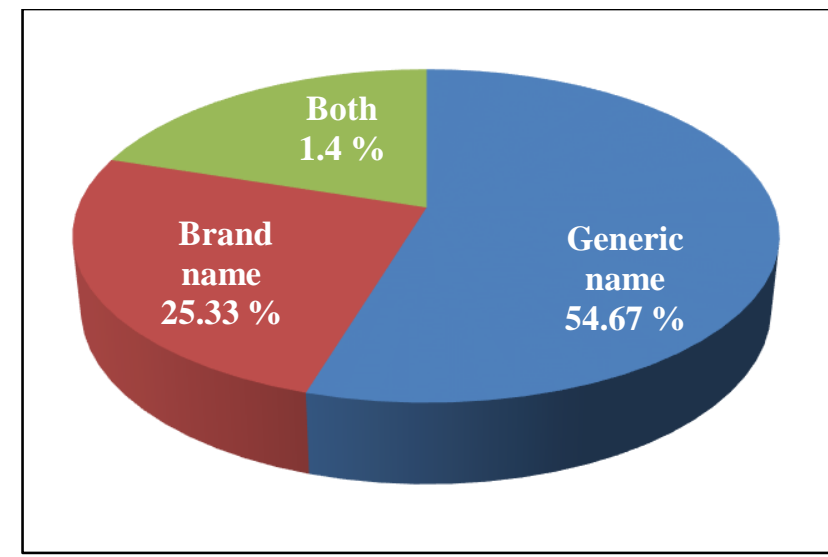

Figure 4: RUM questionnaire 17 (preference to write in a prescription slip).

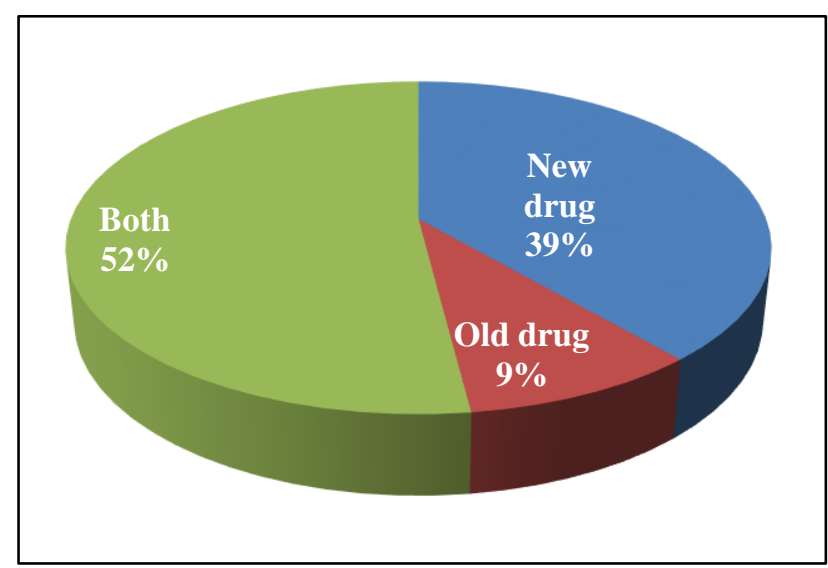

Figure 5: RUM questionnaire 18 (preference to prescribe a new or old drug).

Table 1: Questionnaire - 22 RUM would.

\begin{tabular}{|llllll|}
\hline & $\begin{array}{l}\text { Strongly } \\
\text { agree }(\%)\end{array}$ & $\begin{array}{l}\text { Agree } \\
(\%)\end{array}$ & $\begin{array}{l}\text { Neutral } \\
(\%)\end{array}$ & $\begin{array}{l}\text { Disagree } \\
(\%)\end{array}$ & $\begin{array}{l}\text { Strongly } \\
\text { disagree }(\%)\end{array}$ \\
\hline a) Minimize Adverse Drug Reaction (ADR) & $34(45.33)$ & $35(46.67)$ & $6(8)$ & - & - \\
\hline b) Avoid development of resistance & $38(50.67)$ & $30(40)$ & $6(8)$ & - & $1(1.33)$ \\
\hline c) More safer & $28(37.33)$ & $38(50.67)$ & $9(12)$ & - & - \\
\hline d) Cost-effective & $26(34.67)$ & $28(37.33)$ & $18(24)$ & $3(4)$ & - \\
\hline e) Proper treatment & $34(45.33)$ & $32(42.67)$ & $6(8)$ & $3(4)$ & - \\
\hline f) Improve availability of drugs & $22(29.33)$ & $31(41.33)$ & $20(26.67)$ & $2(2.67)$ & - \\
\hline
\end{tabular}

When prescription $54.67 \%$ prefer generic name and brand name by $25.32 \%$ (Figure 4). 52\% said they prefer to write both old and new drugs (Figure 5). 56.67\%, 53.33\% and $62.67 \%$ were not sure whether Medical representatives (MRs) are the source of knowing about drugs, influences doctor to prescribe irrationally, and reliable with it respectively. $85.33 \%$ said that doctors should listen to MRs and take its own decision before prescribing (Figure $6)$.
There were $92 \%$ agreed that rational prescription would reduce the occurrence of adverse drug reaction (Table 1). Relationship between RUM and drug resistance, cost effectiveness, safer and availability of the drug, proper treatment is shown in Table 1.

Find full Questions in Annexure-1 for Question no 1 - 21 and 23 - 26; for Question no 22 - refer Table 1. 


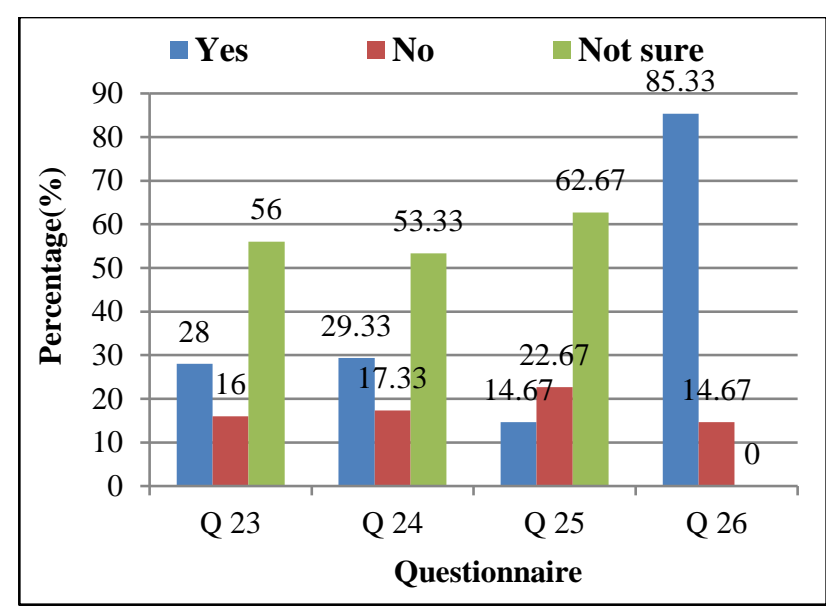

Figure 6: RUM questionnaire 23 to 26 [Medical representatives $(\mathrm{MRs})]$.

\section{DISCUSSION}

This study was designed due to the lack of knowledge and practice among the healthcare professionals, where the initial knowledge beginning from student's level and the practice of the acquired knowledge during their intern training would be great initiative towards improving the rational way of prescription.

Only $57.33 \%$ of the interns were aware of the term RUM, which was less than the Deepthi SV et al, study $(84 \%){ }^{6}$ This shows the lack of knowledge among trainees which need to address and emphasize on educational policy to include the rational use of medicine through all the years of MBBS training. So that the knowledge gap can be decreased. $61.33 \%$ stated that they prescribe the drugs rationally which was more than the interns awareness on term RUM which gives a thought that their may be gap in understanding and the practice of the same. And was less when compared with the Deepthi S V et al study $(71 \%){ }^{6}$ $49.33 \%$ were aware of the term Essential Medicine usage. The awareness in this study on Essential Medicine (EM) was a serious concern where Deepthi S V et al study (79\%) showed $79 \%$ were aware of it. $57.33 \%$ affirm that they prescribe from essential drug list of india. ${ }^{6}$ Which was more than that stated by Deepthi S V et al study $(25 \%){ }^{6}$ $41.33 \%$ were aware of the term P drug $25 \%$ of interns, were aware of the term P drugs. ${ }^{6}$

Less than 5\% could define RUM correctly. Only $30 \%$ of interns could define the same correctly. ${ }^{6}$

With respect to the prescription practices (question no 19, 20,21 ) interns in this study had a fair prescription practices when compared to the Deepthi SV et al. ${ }^{6}$

In this study we received almost similar results to that of the Dakhale et al, but the percentage of response to the statements was quiet less than that of the Dakhale et al, only one student correctly responded to the total number EML of India and Fixed dose combination. ${ }^{7}$ Otherwise quiet a good number of interns were aware of the RUM knowledge and their practices. But there is a scope for improvement in terms of providing safer therapeutic benefits to the patients with the proper training and allowing them to attend CME, conference on RUM.

Around $90 \%$ agreed that RUM can minimize the ADR, avoid resistance development and safer while around $70 \%$ stated it will improve the availability, proper therapeutic practice and cost effective can become a habit of good will. $56 \%, 53.33 \%$ and $62.67 \%$ responded that they were not sure whether the information gathered from medical representatives is of correct one and that influences the irrational prescription practices and reliability of the promotional literature respectively. $85.33 \%$ said that doctor should always think with their updated knowledge to decide and prescribe even though the MR presents aggressively and provocatively to prescribe their drug company products.

Nearly half of the participants were battling with the confusion about rational use of medicine concept. This lack of awareness being pulsating since many decades with policy maker being responsible authority can bring changes in this regard by enforcing the concerned fellows to establish the Drugs and Therapeutic Committees (DTCs) in hospitals. This would take care of the prescribing habit in a right direction. ${ }^{8}$

Adoption of teaching and training methods to have a clearcut picture of Essential Medicine and RUM concept during undergraduate training. Motivating them to participate and involve them in pharmacovigilance programs and prescription audits would give them a double edged sword advantage in bringing down the problem that may arise from ignorance as well as from knowledge scarcity. ${ }^{8}$

The dearth in the concept due to the inadequate training is the present concern where they not competent enough to prescribe confidently because of the more factual knowledge been taught.

But currently the shifting of knowledge is required from being factual to hands on training to impart the practical therapeutic proficiency in prescribing medicines rationally. ${ }^{9-13}$

Nearly more than $50 \%$ were not aware of the P-drug concepts and majority of them were blind with respect to the steps to be followed in selecting P-drug for a particular condition and advantages. However, application of P-drug concept and its implementation along with the rational use of FDC in trainees was missing. ${ }^{4}$ Rahaman et al, study reported that "exercise on the selection of $\mathrm{P}$ drug" improves the performance of the students in clinical pharmacology case report. ${ }^{14}$

Conducting workshops on P-drug concept exclusively for interns might intensify the importance of RUM in their 
daily practice with keeping in mind the golden message given by WHO "Use a medicine only when it is needed."15

Small sample size was the only limitation if the study.

\section{CONCLUSION}

Thus, the main intention that reflects in rational use of medicine in interns should be assessed periodically on prescribing knowledge and skills during their training to minimize prescribing and clinical errors.

\section{ACKNOWLEDGEMENTS}

Authors would like to thank Interns of AIMS 2012 batch for their kind-hearted co-operation.

Funding: No funding sources

Conflict of interest: None declared

Ethical approval: The study was approved by the Institutional Ethics Committee

\section{REFERENCES}

1. World Health Organisation. Rational use of Medicines. Available at: http://www.who.int/medicines/areas/rational_use/en/i ndex.html; 2010. Accessed 14.01.12.

2. Bhatt AD. Drug promotion and doctor: a relationship under change? J Postgrad Med. 1993;39:120.

3. Choudhry NK, Stelfox HT, Detsky AS. Relationships between authors of clinical practice guidelines and the pharmaceutical industry. JAMA. 2002;287(5):612e617.

4. Srinivasan S. A network for the rational and ethical use of drugs. Indian J Med Ethics. 2004;1(1).

5. Srinivasan C. Trained quacks: An Indian drug tragedy. Issues Med Ethics (serial on the internet). 1999;7(2):1. Available at: http://www.issuesinmedicalethics.org/072br063.html. Accessed on 10.01.12.

6. Vagge DS, Muraraiah S, Jayanthi CR, Rohatgi V. A Questionnaire Study to Evaluate the Awareness and Knowledge about Rational Use of Medicines among
Trainee Medical Graduates in a Tertiary Care Centre. Int. J. Pharm. Phytopharmacol. Res. 2013;3(3):231-3.

7. Dakhale G, Pimpalkhute S, Bajait C, Raghute L. Evaluation of Knowledge, Attitude and Practice of Rational use of Medicine Among Interns and Resident Doctors in a Tertiary Care Teaching Hospital. J Young Pharm, 2016;8(2):114-7.

8. Thawani V. Rational use of medicines: Achievements and challenges. Indian J Pharmacol. 2010 Apr;42(2):63-4.

9. World Health Organization. Promoting rational use of medicines: Core components. WHO Policy Perspectives on Medicine. Geneva: WHO; 2002.

10. Desai MK, Panchal JR, Shah S, Iyer G. Evaluation of impact of teaching clinical pharmacology and rational therapeutics to medical undergraduates and interns. Int J Appl Basic Med Res. 2016;6:205-10.

11. Upadhyaya P, Seth V, Sharma M, Ahmed M, Moghe VV, Khan ZY, et al. Prescribing knowledge in the light of undergraduate clinical pharmacology and therapeutics teaching in India: views of first-year postgraduate students. Adv Med Educ Pract. 2012;3:47-53.

12. Alfa J, Adigwe OP. Rational use of medicines in Nigeria: A critical review. J Biol Agric Healthc. 2014;4:89-99.

13. Ambwani S, Mathur AK. Rational drug use. Health Adm. 2006;19:5-7.

14. Rahaman S, Kamal AA, Chaudhary S. Exercise on selection $\mathrm{P}$ drug. Preliminary evaluation of newer method of pharmacology teaching in Bangladesh. Banglad J Physiol Pharmacol. 2000;16:50-4.

15. The Role of Education in the Rational Use of Medicines. SEARO Technical Publication Series No. 45. World Health Organization, Regional Office for South-East Asia. Available at: http://apps.who.int/medicinedocs/documents/s16792e /s16792e.pdf. Accessed on 09/07/2018.

Cite this article as: Shivaraju TP, Savkar MK. Awareness of rational use of medicines among interns at rural teaching hospital. Int J Basic Clin Pharmacol 2018;7:2184-9. 
Annexure 1: Questionnaires on RUM.

1. Are you aware of the term essential drugs?

2. Are you aware that now the term used is essential medicines?

3. Do you always prescribe from the essential drug list of India?

4. Do you have the National Model Essential Drug List at your workplace?

5. Do you know the number of drugs included in Indian Essential Medicines List (EML) If yes specify.

6. Do you know the number of fixed dose combination included in EML, if yes specify.

7. Are you aware of the term Rational Use of Medicines?

8. What is rational use of medicines definition

9. Do you always prescribe rationally?

10. Are you always aware of the ingredients of the drug you prescribe?

11. Are you aware of the term P-drugs?

12. Are you aware of STEP criteria for selection of P-drug?

13. Are you aware of advantages of using P-drug for prescription?

14. Do you inform the patient regarding disease, drug therapy, regular follow up and monitoring of drug therapy?

15. How often do you prescribe essential medicines?

16. Are you aware of the adverse effects, interactions and contraindications of the drugs you prescribe?

17. What do you prefer to write in a prescription slip?

18. What do you prefer to prescribe a new or old drug?

19. Do you take care to write all the parts of prescription?

20. Do you check for full information about the drugs before prescribing?

21. Do you give full information about Adverse effects to your patients

23. Medical representatives (MRs) are a source of getting correct information about the new drugs.

24. MRs Influence doctors to prescribe many irrational drugs.

25. Drug promotion materials provided by the MRs are reliable.

26. Doctors should listen to the MRs- but do what they think appropriate. 